\title{
USE OF AUTOGENOUS AORTIC AND MAIN PULMONARY ARTERY FLAPS FOR REPAIR OF ANOMALOUS ORIGIN OF THE RIGHT PULMONARY ARTERY FROM THE ASCENDING AORTA
}

\author{
Jacques A. M. van Son, MD, and Frank L. Hanley, MD, San Francisco, Calif.
}

In patients with origin of the right (RPA) or left pulmonary artery from the ascending aorta, the RPA or, much less commonly, the left pulmonary artery arises from the ascending aorta in the presence of separate aortic and pulmonary valves and without the interposition of ductal tissue..,2 The RPA usually originates from the right posterior aspect of the ascending aorta. ${ }^{3}$ Physiologically, the alteration creates a large left-to-right shunt. The contralateral lung is therefore subjected to the entire right ventricular output in addition to flow contributed by associated anomalies, such as patent ductus arteriosus, aortopulmonary septal defect, atrial septal defect, or ventricular septal defect, which have been present in greater than $60 \%$ of previous reports. ${ }^{1-4}$ Without early operation the natural history of this condition is dismal, with a mortality rate of approximately $70 \%$ at 6 months of age and $80 \%$ at 1 year of age. 5

Armer and associates ${ }^{6}$ reported the first successful anatomic repair of anomalous origin of the RPA from the ascending aorta with interposition of a polyester fiber graft between the RPA and the main pulmonary artery (MPA). The first successful primary repair was reported by Kirkpatrick, Girod, and King. ${ }^{7}$ Traditionally, primary repair is generally reserved for those patients in whom the RPA originates from the posterior aspect of the aorta in close proximity to the MPA. ${ }^{8}$ When the RPA arises from the right lateral aspect of the aorta, the right hilum is often mobilized medially to allow apposition of the RPA and MPA without tension. Alternatively, an interposition synthetic graft is placed either anterior or posterior to the aorta. ${ }^{5,9}$ We propose a modified native tissue repair that reduces tension on the RPA-MPA anastomosis.

The ascending aorta, proximal aortic arch vessels, the MPA, and both branch pulmonary arteries are widely mobilized. As soon as cardiopulmonary bypass has been established, the RPA is temporarily clamped or snared. The patent ductus arteriosus, if present, is doubly ligated and divided. After crossclamping of the aorta, the anterior aortic circumference is incised transversely at the level of the RPA origin (Fig. 1). Under direct vision, the remaining aortic circumference is transected, with a generous cuff of posterior aortic wall left around the RPA origin (Fig. 2). Alternatively, the posteromedial aspect of the aortic wall can be left intact. Utmost care should be taken to avoid compromise of the left

From the Division of Cardiothoracic Surgery, University of California at San Francisco, San Francisco, Calif

Accepted for publication March 16, 1995.

Address for reprints: Jacques A. M. van Son, MD, Herzzentrum, University of Leipzig, Russenstrasse 19, D-04289 Leipzig, Germany.

J Thorac Cardiovasc Surg 1996;111:675-6

Copyright (C) 1996 by Mosby-Year Book, Inc.

$0022-5223 / 96 \$ 5.00+0 \quad \mathbf{1 2 / 5 4 / 6 6 3 3 5}$ coronary ostium. An anteriorly hinged trapdoor incision is made in the MPA, opposite the origin of the left pulmonary artery, so that an anterior flap of MPA tissue is created to balance against the posterior aortic flap on the RPA (Figs. 1 and 2). Subsequently, the RPA is anastomosed to the MPA with 7-0 polyglyconate suture (Maxon, Davis \& Geck, Inc., Danbury, Conn.) with the two flaps forming the proximal segment of the RPA (Fig. 3). Finally, the ascending aorta is reconstructed with a similar suturing technique (Fig. 4); alternatively, the defect in the aortic wall at the origin of the RPA may be closed with a small prosthetic patch.

This technique was successfully applied in a 5-week-old male infant who had been observed and treated for congestive heart failure with pulmonary hypertension. A preoperative echocardiogram demonstrated an anomalous RPA from the right lateral aspect of the ascending aorta and a large patent ductus arteriosus. The postoperative course was uneventful. Four months after the operation the infant was thriving with an echocardiographically demonstrated increase in proximal RPA diameter from $6 \mathrm{~mm}$ (at the time of the operation) to $8 \mathrm{~mm}$.

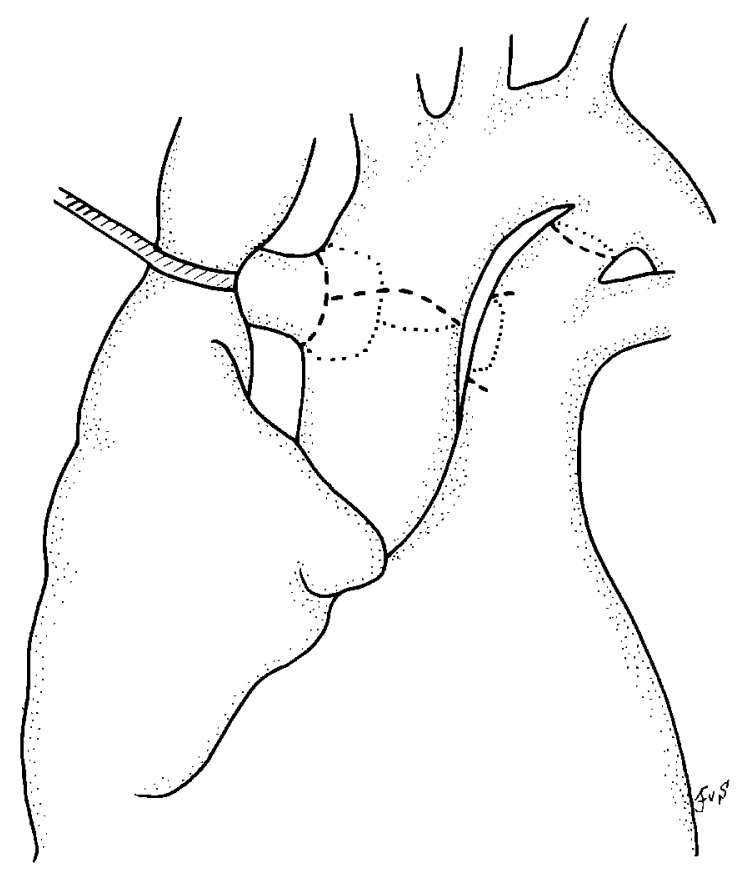

Fig. 1. After double ligation and division of the patent ductus arteriosus, the anterior circumference of the ascending aorta is transected transversely at the level of the anomalously arising RPA. The incisions for creation of a posterior aortic tissue flap and an anteriorly hinged MPA tissue flap are indicated. 


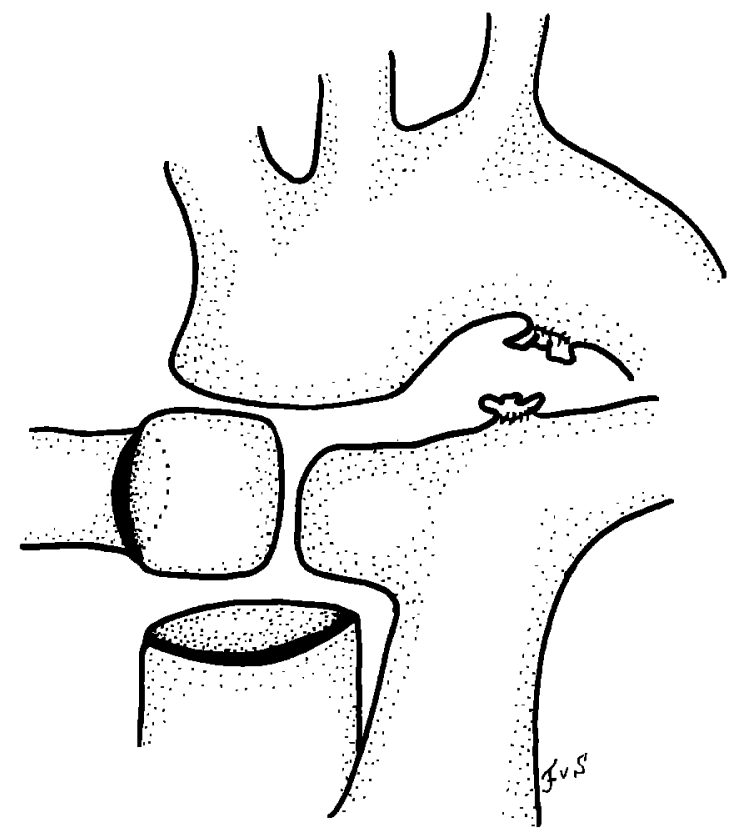

Fig. 2. Posterior aortic and anterior MPA tissue flaps have been created.

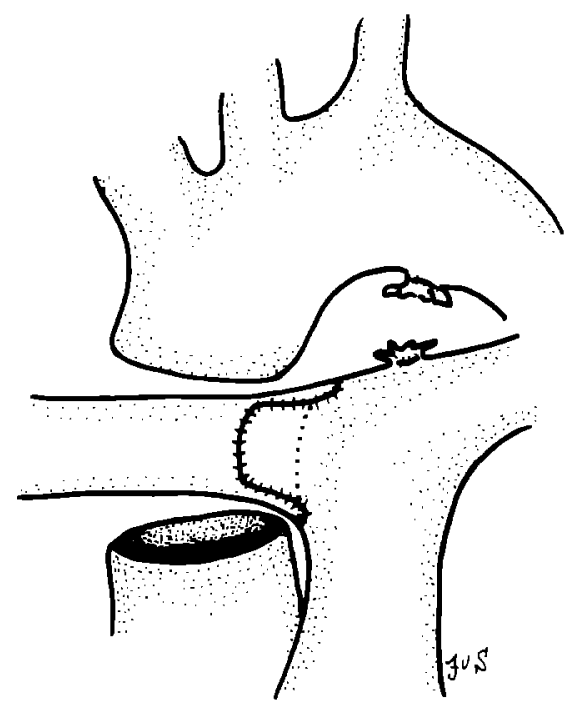

Fig. 3. Both tissue flaps are anastomosed with a running 7-0 polyglyconate suture, thereby creating a proximal extension of the RPA.

Anatomic correction of anomalous origin of the RPA from the ascending aorta by direct anastomosis is preferable to the interposition of a prosthetic graft, because the latter technique fails to accommodate larger flow volumes with growth of the patient. ${ }^{8,10}$ Because the RPA frequently arises from the right lateral aspect of the aorta, direct anastomosis without undue tension may not always be feasible. In such cases, the modification reported here may be advantageous to allow for extra length of the proximal RPA. As opposed to the use of an interposition graft, this modification has all of the advantages of exclusive use of native tissue, including

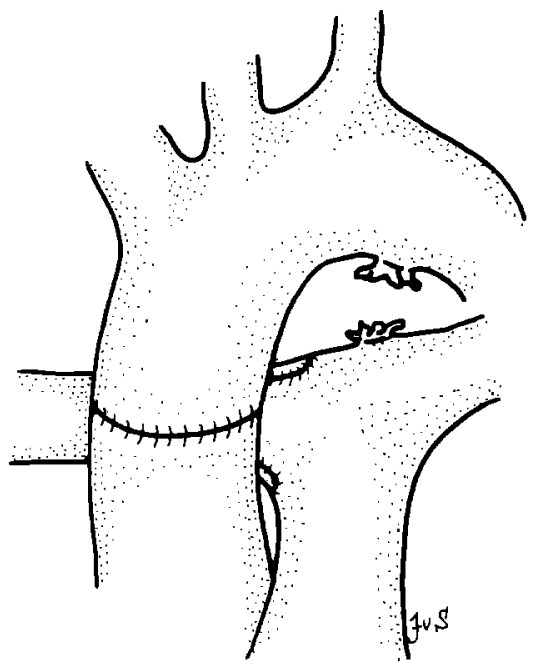

Fig. 4. The ascending aorta is reconstructed anterior to the RPA-MPA anastomosis.

growth potential during childhood, reduced risk of thrombus formation, and lower infection rate. The posterior aortic and anterior MPA tissue flaps serve as an extension between the RPA proper and the MPA, thereby reducing tension on the RPA-MPA anastomosis and decreasing the risk of kinking or stenosis of either branch pulmonary artery.

\section{REFERENCES}

1. Kutsche LM, Van Mierop LHS. Anomalous origin of a pulmonary artery from the ascending aorta: associated anomalies and pathogenesis. Am J Cardiol 1988;61:850-6.

2. Keane JF, Maltz D, Bernhard WF, Corwin RD, Nadas AS. Anomalous origin of one pulmonary artery from the ascending aorta: diagnostic, physiological and surgical considerations. Circulation 1974;50:588-94.

3. Calder AL, Brandt PWT, Barratt-Boyes BG, Neutze JM. Variant of tetralogy of Fallot with absent pulmonary valve leaflets and origin of one pulmonary artery from the ascending aorta. Am J Cardiol 1980;46:106-16.

4. Penkoske PA, Castaneda AR, Fyler DC, Van Praagh R. Origin of pulmonary artery branch from ascending aorta: primary surgical repair in infancy. $\mathrm{J}$ THORAC CARDIOVASC SURG 1983;85:537-45.

5. Fontana GP, Spach MS, Effmann EL, Sabiston DC Jr. Origin of the right pulmonary artery from the ascending aorta. Ann Surg 1987;206:102-13.

6. Armer RM, Shumacker HB, Klatte EC. Origin of the right pulmonary artery from the ascending aorta: report of a surgically corrected case. Circulation 1961;24:662-8.

7. Kirkpatrick SE, Girod DA, King H. Aortic origin of the right pulmonary artery: surgical repair without a graft. Circulation 1967;36:777-82.

8. Sibley YDL, Roberts KD, Silove ED. Surgical correction of anomalous origin of right pulmonary artery from aorta in a four day old neonate. Br Heart J 1986;56:98-100.

9. Kuypers PJ, van der Maas AH, Busch HJ. Origin of the right pulmonary artery from the aorta with patent ductus arteriosus. J Thorac Cardiovasc SuRg 1969;57:185-9.

10. Semb BKH, Björnstad PG. Correction of isolated anomalous origin of the right pulmonary artery from the ascending aorta. Thorac Cardiovase Surg 1981;29:255-8. 